\title{
The future of human civilisation, hydrogen civilisation: theoretical and humanitarian-cultural groundwork of the transition
}

\author{
Victor A. Goltsov \\ Donetsk National Technical University, \\ 58, Artyom Street, 83000 Donetsk, Ukraine \\ E-mail: goltsov@physics.dgtu.donetsk.ua
}

\begin{abstract}
A new vision of the future human civilisation, hydrogen civilisation (HyCi) is generalised. At this rigorous, severe historical period human kind still has a real possibility to save the biosphere and make living out of humanity a possible and real process. The above objective can be achieved only by advantageous all-planetary work along the direction of the ecologically clean and economically sustainable vector 'hydrogen energy $\rightarrow$ hydrogen economy $\rightarrow$ HyCi'. The HyCi concept includes three constituent, mutually conditioned parts: industrial-ecological, humanitarian-cultural and geopoliticalinternational legislative ones. This paper presents a comprehensive and analysed theoretical and humanitarian-cultural groundwork of the transition. The legislative-economic mechanism of the transition to $\mathrm{HyCi}$ is formulated, and the way to a hydrogen market economy - the economic basis of the $\mathrm{HyCi}-$ is indicated and discussed.
\end{abstract}

Keywords: hydrogen energy; hydrogen economy; hydrogen civilisation; HyCi.

Reference to this paper should be made as follows: Goltsov, V.A. (2011) 'The future of human civilisation, hydrogen civilisation: theoretical and humanitarian-cultural groundwork of the transition', Int. J. Nuclear Hydrogen Production and Applications, Vol. 2, No. 3, pp.159-177.

Biographical notes: Victor A. Goltsov is a member of the Board of Directors of the International Association for Hydrogen Energy (IAHE), a member of the Honorary Editorial Board of the International Journal of Hydrogen Energy (IJHE), an Editorial and Scientific Committee of International Journal of Nuclear Hydrogen Production and Application (IJNHPA), the Chairman of the Physics Department and the Head of the Donetsk State Hydrogen Laboratory of the Donetsk National Technical University. Over several decades he has been elaborating hydrogen-materials problems and general questions of hydrogen energy. During the first years of the 21 st century he has been steadily elaborating the hydrogen civilisation concept $-\mathrm{a}$ far-distant historical vision of a sustainable humankind future. He was awarded the IAHE Rudolf Erren Award (June 2000) for 'Outstanding Contributions to Hydrogen Energy, in General, and to Hydrogen Treatment of Materials, in Particular'. 


$$
\begin{array}{r}
\text { Over and again have nations and civilisation } \\
\text { have been confronted with problems, which, } \\
\text { like the riddle of the Sphinx, } \\
\text { not to answer was to be destroyed. } \\
\text { 'Social Problems' } \\
\text { Henry George } \\
(1830-1897)
\end{array}
$$

\section{Introduction: historical view of hydrogen}

Hydrogen is an effective source of energy. Ideas associated with hydrogen have been systematically attracting the attention of scientists and engineers for about 200 years. But, as is well known from science and technical history even the greatest fundamental ideas give rise to public echo and may be realised in the life only and only in the time, when there appears an industrial suitable demand and public aspiration (Goltsov, 2008; Vernadsky, 1988).

In accordance with this historical tendency, the hydrogen idea had its origin and development in the 20th century. Really, in the 20th century there was completely formed the economy based on fossil fuels (first of all on oil and natural gas). Side by side with a permanent achievement of successes, the oil and gas economy has gradually and inevitably led mankind to a worldwide ecological catastrophe and global geopolitical shocks (exhaustibility of the world resources of oil and gas and because of an inadequate awareness of a world ecological catastrophe threat).

Environmental hazards of this way of life were deeply understood already in the first half of the 20th century. The great thinker V.I. Vernadsky, the founder of the biospheric and noospheric studies, perceived both the geological vastness of human activity, and the unpredictability of its consequences (Vernadsky, 1929, 1945, 1991). He wrote: "we observe a more and more dramatic influence of a human intellection and collective mind on geochemical processes"; "of special interest and a characteristic fact in the history of carbon, is the fact that carbon dioxide increases as the history of civilisation evolves"; "in this way a civilised person disrupts the equilibrium established on the Earth". He emotionally stressed, "here human beings behave not like Homo sapiens but like Homo sapiens faber". He exclaimed, "where will this new geological process stop? And will it stop or not?"

In the first half of the 1970s, thanks to the enthusiasm of conscientious representatives of the world scientific community (Bockris, 1971, 1972; Gregory, 1973; Marchetti, 1974; Ohta, 1974; Veziroglu, 1975; Veziroglu and Basar, 1974), the fantastic idea of the great French writer Jules Verne was revived. This idea was firstly written in Verne's A Mysterious Island in 1874. It concerns the opportunity for future humanity to heat itself with water, dissociating it into hydrogen and oxygen and then burning hydrogen. Indeed, as is well known, hydrogen burning does not pollute the atmosphere. One can find reviews of this hydrogen romantic's era in Bockris (2001), Veziroglu (2000) and Legasov (2007).

At the height of the fuel and energy crisis of the 1970s during the hydrogen economy miami energy (THEME) Conference (18-20 March, 1974) organised and chaired by T. Nejat Veziroglu, the consensus developed that the hydrogen energy system offers the optimum solution to the interrelated global problems. And in 1974, the International 
Association for Hydrogen Energy (IAHE) was established (Dr. Veziroglu, Founding President) with its headquarters in the Clean Energy Research Institute of Miami University (USA). IAHE began publishing the International Journal of Hydrogen Energy $(I J H E)$, and started organising the biennial World Hydrogen Energy Conferences (WHEC) to provide a platform for forming the hydrogen energy community (Veziroglu, 2000).

During the same time in the USSR, owing to the activity of Valery A. Legasov, Anatoly N. Podgorny and their scientific adherents, hydrogen energy started to be intensively researched. A wider energy-technological version of the hydrogen energy concept, namely 'nuclear hydrogen energy and technology' was steadily worked out by the Institute of Atomic Energy, named by I.V. Kurchatov, and some other scientific and technological organisations. As a result, there was an official acceptance of the concept and the USSR joined the IAHE (Legasov, 1978-1988).

In accordance with the agreement between T.N. Veziroglu and V.A. Legasov, the Donetsk state hydrogen laboratory and the Institute of Atomic Energy prepared IJHE annual reports about the 'hydrogen' works published in the Soviet Union (Alimova et al., 1983-1994). There was established a partnership for ongoing scientometric investigation of the development of hydrogen energy and the world hydrogen movement.

In the 1970s and 1980s the concept of hydrogen energy was fully developed and worked out in great details, its scientometric analysis was done, and its structure was designed (Goltsova et al., 1990). Later, under the influence of commercialisation of hydrogen technique and technology (hydrogen automobiles, fuel cells, hydrogen-nickel batteries, improved electrolysers, etc.), the hydrogen energy concept transformed and the concept of hydrogen economy became firmly established.

At the end of the 20th century, human activity in use of fossil fuels approached an unreasonable scale and the world biosphere and climate catastrophe became a near historical threat. Following after Vernadsky it became possible to say with a sorrowful irony: "now human beings behave not like Homo sapiens faber but like Homo desipiens faber, a man working without mind" (Goltsov, 2001a). In another words, we are approaching (or may be have already entered) a civilisation of Homo desipiens faber. Really, deterioration of the biosphere arises from a rational framework: greenhouse effect, global warming and degradation of climate; ozone layer depletion, ozone holes appearance and their growth; acid rains; degradation and decrease of productive soil (see also Appendix 1).

Now, I would like to recall a deep thought of the great American thinker Henry George, which is an epigraph of this work, and repeat the last its sentence: "not to answer was to be destroyed".

Thinking on the basis of Vernadsky's biosphere and noosphere doctrine (see Appendix 2) about this human dilemma (to be or not to be) and leaning upon hydrogen economy advances, has led to a novel understanding of the future of human civilisation, the hydrogen civilisation (HyCi). And a novel large-scale $\mathrm{HyCi}$ concept has been conceived (Goltsov, 2001a, 2001b). So, for the first time, the main aspects of a move into the era of an ecologically clean $\mathrm{HyCi}$ were being pondered. Some biospheric and noospheric consequences of this transition were analysed, and the tasks of the world hydrogen movement formulated.

It was perceived (Goltsov, 2001a, 2001b) that a historically prolonged movement into the era of $\mathrm{HyCi}$ will lead to global transformations in all aspects of human existence, 
human mentality and human society, the mode of political and international thought, environment and hydrogen industry friendly development. For the first time this planetary problem has been raised officially at the International Vernadsky's Conference in the Donetsk National Technical University (Donetsk, Ukraine, April 10-12, 2001) (Goltsov, 2001a, 2001b). At the plenary session V.A. Goltsov adduced arguments and called up: "negative climate and biosphere changes analysed on the basis of Vernadsky's doctrine make HyCi transition to be especially acute for thinking out just now, not at a later time!"

Now let us note some milestones in the development of the HyCi concept. In 2001, the first worldwide international discussion on the $\mathrm{HyCi}$ concept was presented by Goltsov and Veziroglu (2001a) during the Third International Conference 'HTM-2001' (Donetsk, Ukraine, May 14-18, 2001). Scientists and industrialists from Russia, the USA, UK, Ukraine, Japan, France, Poland and other countries discussed the $\mathrm{HyCi}$ concept and accepted the 'memorandum on the transition from fossil system to hydrogen economy and then to HyCi'. The memorandum was published in a special issue of IJHE (Goltsov, 2002). The views of the HyCi concept on the future of humanity on a global scale were published in IJHE in 2001 (Goltsov and Veziroglu, 2001b). Further development of the HyCi concept was realised in Goltsov and Goltsova (2003a, 2003b), Ohta (2004, 2006), Goltsov et al. 2006a, 2006b, Goltsov (2007a, 2007b, 2007c).

On June 12, 2002 at the meeting of board of directors of IAHE held in Montreal (WHEC-14), pioneered by Board Director Dr.. J. Bolcich, discussion of the novel IAHE HyCi concept took place and the presentation of the IAHE HyCi concept to the world hydrogen movement at the 15th World Hydrogen Energy Conference in Yokohama was recommended. This decision was fulfilled in the 30th anniversary year of the IAHE during the 15th World Hydrogen Energy Conference (Yokohama, Japan, June 27-July 2, 2004) (Goltsov et al., 2004). The concept was presented at the plenary session to an audience of 2,000 delegates from 52 countries. Following this, in the first years of the 21st century the novel IAHE HyCi-concept was widely presented to the scientific community at the international hydrogen conferences: Istanbul-2005, Moscow-2006, Lyon-2006, Berlin-2006, Istanbul-2007, Donetsk-2007, Montecatini Terme-2007, Moscow-2008, and Xi'an-2008, and were published in IJHE (2006), IJNHPA (2006) and in many other journals and conference proceedings.

Comprehensive data on the current $\mathrm{HyCi}$ concept status in the world hydrogen movement are well represented by 'memorandum on a novel IAHE conception of $\mathrm{HyCi}$ of the future: historical aspects and new challenges of the present day' (Goltsov, 2008). For additional information see the daily report no. 3 of WHEC-16 in Lyon, France (Appendix 3).

\section{The essence of $\mathrm{HyCi}$ concept}

The general principle of HyCi concept is this: humanity can preclude world ecological catastrophe and conserve the biosphere's ability to sustain life only by movement along the vector: 'hydrogen energy $\rightarrow$ hydrogen economy $\rightarrow$ hyci'. The HyCi concept has a program nature and consists of interrelated and mutually conditioned basic constituents: industrial-ecological, humanitarian-cultural, geopolitical-international legislative ones.

The industrial-ecological constituent of the $\mathrm{HyCi}$ concept has its origins in the progress of hydrogen economy and encompasses the historical scientific viewpoint on 
interrelated development of the world ecological situation and hydrogen industry on a global scale. Being based on Vernadsky's studies concerning the biosphere, the HyCi concept leans in its analysis upon synergetics, a modern science about the development of complex self-organising systems, of which the biosphere is an example. The important points of the industrial-ecological constituents: climate, ecology, human environments and industrial and other activities, are nothing more than the biosphere's functions and a manifestation of the nature of the biosphere. So, correct viewing and solving of the above problems can be entirely refined from the biosphere angle only.

The humanitarian-cultural constituent of the $\mathrm{HyCi}$ concept emerges from Vernadsky's studies about the noosphere and his cultural-philosophical heritage. In its development, this part of the $\mathrm{HyCi}$ concept is guided by the humanities: modern philosophy, culturology and others. Distinctive standpoint of humanitarian-cultural constituent: mass and elitist hydrogen-ecological consciousness is a spiritual basis of human civilisation of the future, HyCi. Correspondingly, hydrogen-ecological consciousness introduction is to be of the most important objective in the coming decades. So, the historical task of the HyCi concept in its humanitarian-cultural aspect consists of the ideology formation and propagation of hydrogen-ecological and noospheric consciousness of people of some countries firstly, and then of all humanity.

With regard to the geopolitical-international legislative constituent of the $\mathrm{HyCi}$ concept, the conversion 'Hydrogen energy $\rightarrow$ hydrogen economy $\rightarrow$ HyCi', being an all-planetary process, should be resolved in the frames of the world legislative field elaborated by international and national organisations, first of all under the auspices of the UN and its structural organisations (UNIDO, UNESCO, etc.). Transition to the hydrogen economy and then to the HyCi will undoubtedly be accompanied by permanent global and/or local geopolitical and geoeconomic contradictions. In particular, changes in the national interests of many countries will take place - 'old' and 'new' energy resource owners, changes of geoeconomic interests of transnational energy companies. A polarity reversal might arise in the sphere of geopolitical and geoeconomic attractions and the like. The generalised task of the political elite and of all humankind is to work steadily under legislative (not by force) governing of possible negative geopolitical and geoeconomic tendencies of the movement on the road to $\mathrm{HyCi}$.

The framework laws (recommended by international organisations to the national parliaments and governments), which would outline scientifically and economically founded ways and mechanisms for the transition to $\mathrm{HyCi}$, are to be accepted.

National parliaments on the basis of framework laws must accept national laws taking into account specific conditions of individual countries, the living standard of the country, its economic state, scientific potential, and environment and so on. The designing and adoption of national laws should be followed by regulation of financing and establishing of comprehensively organised national enterprises, which would encourage the use of hydrogen, investment of private capital and the establishment of a competitive market for the power hydrogen.

The transition into the era of $\mathrm{HyCi}$ will be a particularly synergetic multilayer process and all constituents of the $\mathrm{HyCi}$ concept (industrial-ecological, humanitarian-cultural, geopolitical-international legislative) will be realised and transformed interdependently and in a mutual coordination.

Specific HyCi concept statement: a novel vision of hydrogen energy and hydrogen economy: 
Hydrogen energy and hydrogen economy are technical, economic and ecological groundwork of the conversion to the future of human civilisation, hydrogen civilisation. It means that any hydrogen energy and economy advance, and any new investigation of its partial problems, is a step forward on the road to hydrogen civilisation.

In this paper, I have raised the necessity and timeliness to start discussion on the theoretical bases of the $\mathrm{HyCi}$ concept and the humanitarian-cultural groundwork of human movement into the era of $\mathrm{HyCi}$.

\section{Public HyCi ideal: can it serve as a superattractor for the humankind?}

Vernadsky $(1929,1945,1991)$, the greatest thinker of the 20th century, distinguished the following types of human thought: scientific, philosophical, religious and artistic - and he underlined their relative independence, and their deep interrelation and interaction. Many times he had also highly stressed the fundamental importance of mutual influence of different types of thinking on the history line of human thought motion, on scientific worldview change over a human history.

In respect to philosophy, Vernadsky wrote:

"I look at the significance of philosophy for the development of knowledge in quite another way than the majority of naturalists..." "Philosophy always comprises the germs which sometimes even anticipate whole areas of a future development of science, and only thanks to a simultaneous work of human minds in such a manner can we get a correct picture of inevitably schematic formation of natural science. In the history of a scientific thought one can clearly and exactly trace such a meaning of philosophy as the background and vital atmosphere of scientific thinking." (Vernadsky, 1991)

On the other hand, advances of the natural sciences influence philosophical thinking, and in some cases, the formation of new philosophical systems. So, in the 1970s there appeared (on the base of the physics of complex physical phenomena and devices) and then started its intensive development an interdisciplinary science - synergetics ${ }^{1}$ that describes the development and self-organisation of greatly non-equilibrium (in a thermodynamic sense of the word), complex, dissipative systems consisting of a large number of subsystems (Haken, 1983a, 1983b,1991). These synergetic systems constantly exchange energy and substance with the outer world. Thanks to this very 'pumping' from the outside, their hierarchical self-organisation can be maintained for a long time and can exist independently until the so-called bifurcation point (period) is reached. During the bifurcation, a synergetic system is in the highest unstable state. Under the influence of a random, small (fluctuation) influence the system can irreversibly transform into a new state quite different both from the initial and any other possible states.

The ideas of synergy and a synergetic way of thinking have quickly penetrated into natural and technical sciences, into biology, geology, archaeology, meteorology, sociology and other sciences. In the 1990s, a synergetic way of thinking came into philosophy and history (Malyshev, 2003; Zubakov, 2003, 2007). A new trend was formed in philosophy, and a philosophical synergetic picture of a social reality comprising a human being, society, culture and consciousness started to be constructed. 
At these very years, as outlined above, the world scientific and engineering thinking on the base of Vernadsky's studies was finding its way into a new understanding the future of human civilisation, $\mathrm{HyCi}$.

From the viewpoint stated above, it is natural to put a question on a correlation and possible mutual complementarity of a philosophical synergetic concept of the universe and the concept of $\mathrm{HyCi}$. In view of the limited size of this publication, let us decide in favour of only one very important, and maybe even a central, question of a mutual complementarity of two concepts under consideration, namely on the meaning content of one of the main philosophical notions - 'superattractor' - and how this notion can be interpreted and highlighted when introduced into the essence of the HyCi concept.

Let's first summarise a philosophical matter of the notion 'superattractor' as it is treated in the synergetic concept of the universe (Malyshev, 2003). 'Superattractor' is nothing else but a product of 'realisation of an absolute ideal', 'a result of realisation of a public ideal'. Then, the sense of history is just a perpetual 'synergetic' motion of a human being to a superattractor. The perpetual motion to the superattractor is therewith of an asymptomatic character of approximating to an 'absolute public product'. Just an asymptomatic character of this motion fills history with an infinitely deep sense, makes its sense inexhaustible: 'every time there is reached a stage in the advance towards this product, from its top there is opened up a new panorama full of even more exciting treasures, and a new stage starts. Since an absolute product cannot be practically reached within a finite historical period, in mankind's awareness it appears as some spiritual 'sky' that must become a focus of all human efforts.

Everything stated above fully reflects the style, logic, integrating character and a finite directivity of a philosophical thinking as such, and at the same time, according to Vernadsky (as it was said above: 'philosophy always comprises germs, the latter sometimes surpassing whole branches of a future development of science ...').

Let's analyse the correlation of the synergetic concept of the universe and the $\mathrm{HyCi}$ concept and formulate the main questions in the following way:

- Is the ideal of $\mathrm{HyCi}$, as it shown in the $\mathrm{HyCi}$ concept, a result of a public (absolute) ideal realisation?

- Can the HyCi concept and the very ideal of $\mathrm{HyCi}$, serve as a superattractor for mankind?

- How does such a concretised superattractor correspond to its philosophical 'germ' and its philosophical properties? May it be useful for scientific and engineering thinking?

It is the author's opinion that answers to these questions put forward are undoubtedly positive. Really, $\mathrm{HyCi}$ is in a certain sense a 'germ' of the historical evolution of an idea quite attractive for mankind. In its origins (the 19th century), this idea initiated from J. Verne's idea, very fantastic for that time (the novel A Mysterious Island, 1874), on a possibility for mankind to heat with the help of water, first decomposing it into hydrogen and oxygen and then burning hydrogen ${ }^{2}$.

As stated in the introduction, in the second half of the 20th century J. Verne's great idea was revived on a new level as a very brave scientific and engineering hypothesis and then like a technical practice (hydrogen energy - hydrogen economy). In the beginning of the 21 st century an outstanding hydrogen idea of Verne got its completeness in the 
concept of $\mathrm{HyCi}$ of the future. So, in the $\mathrm{HyCi}$ concept there is laid the groundwork for a great human ideal, passed through its historical evolution, to save the Earth's biosphere favourable for life by implementing the movement of mankind along the ecologically clean vector 'hydrogen energy $\rightarrow$ hydrogen economy $\rightarrow$ HyCi'.

Obviously, HyCi both in its conceptual essence and by its accomplished historical maturity, by its attractivity as a public ideal can (and will) perfectly serve as a superattractor striving for which will fill the forthcoming history of mankind with a new sense.

In accordance with the philosophical concept of the synergetic universe, an advance to this defined by a scientific thought-specific superattractor will have an asymptotic character of approximating to an 'absolute product'. In this perpetual motion, from the top of every completed stage of evolution 'there is opened a new panorama full of even more exciting treasures, and a new stage begins' (Malyshev, 2003). This philosophical statement will undoubtedly serve as a 'germ' of a further intensification of the $\mathrm{HyCi}$ concept development. Here, a new work of a scientific thought will be needed and, first of all, in the direction discussed below.

Today, we can define at least two historical stages (two phases) in the asymptotic motion of mankind to $\mathrm{HyCi}$ as a superattractor. According to the HyCi concept, at the first initial stage the biosphere will enter into 'the epoch of its renaissance', and the ecological conditions of the existence of mankind will be saved and even improved to some extent. At this stage, to produce hydrogen mankind will still use non-renewable sources of primary energy: atomic energy, fossil fuels, and in future - thermonuclear energy. The use of renewable sources of energy (the sun and its derivatives) at this stage will take place but in a limited scope (for economic-technical reasons only $10 \%-20 \%$ of the total power consumption). It's quite clear that the very idea of a possibility of a favorable development of the biosphere at the first stage of moving to a $\mathrm{HyCi}$ is just a 'spiritual sky' for the human awareness of our time (when they think more, and quite soundly, about a world ecological and climate catastrophe).

On reaching this stage in the asymptotic motion to the superattractor, according to the synergetic concept of the universe, "a new exciting panorama will open and a new historic stage will begin". Within the HyCi concept they think that the evolution of this following historical stage will be initiated and supported by more and more direct use of the sun's energy (and its derivatives) when producing hydrogen for energy life-support of mankind. It is evident that at this historically distant stage, the biosphere will undergo transformations the analogues of which the biosphere didn't have in its geological and historical past. On the one hand, elementary calculations show that if, for example, the Sahara surface is covered with semi-conductor solar batteries then the energy obtained will be enough to provide the life-support of the whole of mankind. On the other hand, realisation of projects of such a scale [this is the work for a 'superman' and 'super-mankind' (Malyshev, 2003)] will inevitably change the fixed power balance of the biosphere with all the unpredictable consequences ${ }^{3}$. In accordance with this, the problems of forming a renovated superattractor that could be accepted by mankind as 'a product of realisation of an absolute ideal' will come forward at this new historical stage. A philosophical thinking therewith gives us the following picture: '...forming this ideal, people possessing gigantic possibilities of transforming the outward things and themselves of all the possibilities choose those that are in a good agreement with the ethics and aesthetic norms imposed by absolute morals and absolute beauty" (Malyshev, 2003). 
Concluding this chapter of the work, let us repeat that a philosophical sense of history is just in the process of the permanent synergetic human motion to a superattractor. The $\mathrm{HyCi}$ concept and future transition into the era of $\mathrm{HyCi}$ fill this philosophical paradigm (this spiritual 'sky') with a specific practical content. At the same time, it is evident that, under the influence of philosophy, the main points of the $\mathrm{HyCi}$ concept will be more generally comprehended later.

\section{Humanitarian-cultural groundwork and legislative-economic mechanism of the $\mathrm{HyCi}$ transition}

A historical task of the $\mathrm{HyCi}$ concept in its humanitarian-cultural aspect consists in forming an elitist and mass hydrogen-ecological and noospheric consciousness in separate leader-countries, and then in the whole world.

Just the humanitarian-cultural formation of the elitist and mass hydrogen-ecological consciousness will allow:

- $\quad$ to approve necessary international legal norms regulating the order of solving inevitable geopolitical and geo-economic problems and to develop pattern laws (recommended as a specimen for national parliaments and governments), regulating the ways and perspectives of passing into $\mathrm{HyCi}$

- to adopt national laws regulating the legal and financial guaranteeing of using the power of hydrogen, defining the ways and trends of state financial support and mechanisms of attracting private capital to establish a competitive market for the power of hydrogen, etc.

- to provide a legislative-economic mechanism of the HyCi transition to be functional.

This new hydrogen-ecological comprehension of mankind elite cannot be based on the idea of prohibiting an expansion of energy consumption in the manner of Kyoto Protocol'. It must be and will be based on the real, permanently adjustable results of the system predictive and analytical study of biosphere functioning as a whole (and its separate systems) for the next 50-100 years by the scenarios taking into account the ways and scope of using the power of hydrogen in world industry, transport, and private life.

Now, let us pay attention to hydrogen-ecological mass consciousness. It's consecutive formation and degree of evolution will finally determine that mankind will either adopt or not adopt motion into the era of $\mathrm{HyCi}$. A historical necessity for changing the mass consciousness when passing into the era of the ecologically clean $\mathrm{HyCi}$ is determined by the following.

The economy of the 20th century was based on a permanent growth of human needs in 'things and services'. The consumption of more and more 'things and services' was and is considered to be an equivalent of a high quality life.

Progressively increasing production $\leftrightarrow$ outrunning consumption (demands) is the 20th century central economic dilemma, which still determines life nowadays. Correspondingly, to have more 'things and services' is a paradigm of modern life.

However, during the last decades the integral indications of the real quality of life gradually reduced more and more (Zubakov, 2003, 2007; see also Appendixes 1 and 3). 
The World Health Organisation (WHO) data shows that $6 \%$ of all deaths are the direct result of environmental pollution.

Independent experts have come to a conclusion on unfavourable tendencies in the development of modern economy and modern society. It's necessary to understand that the gross domestic product (GDP) or the gross national product (GNP) fixes not only the increase in useful production, but also includes human activities that are harmful to society, for example, gambling industry, porno-business and other businesses serving negative Homo decipiens demands. Zubakov (2007) formulated that the GNP shows the market dynamics only - the more demands, the higher the GNP.

A new more complicated and complex "index of a real progress (IRP) is a genuine progress index (GPI)", suggested by Cobb in 1989 (see Zubakov, 2007), including more than 20 indicators of the environment, health, education and state of natural resources, and giving quite another evaluation of the modern social and ecological situation. For example, in the USA (Figure 1) over the period 1950 to 1995, the GNP per capita more than doubled, while the GPI over the period 1975 to 1995 decreased by $45 \%$.

Figure 1 A historical tendency of changing life conditions in the USA

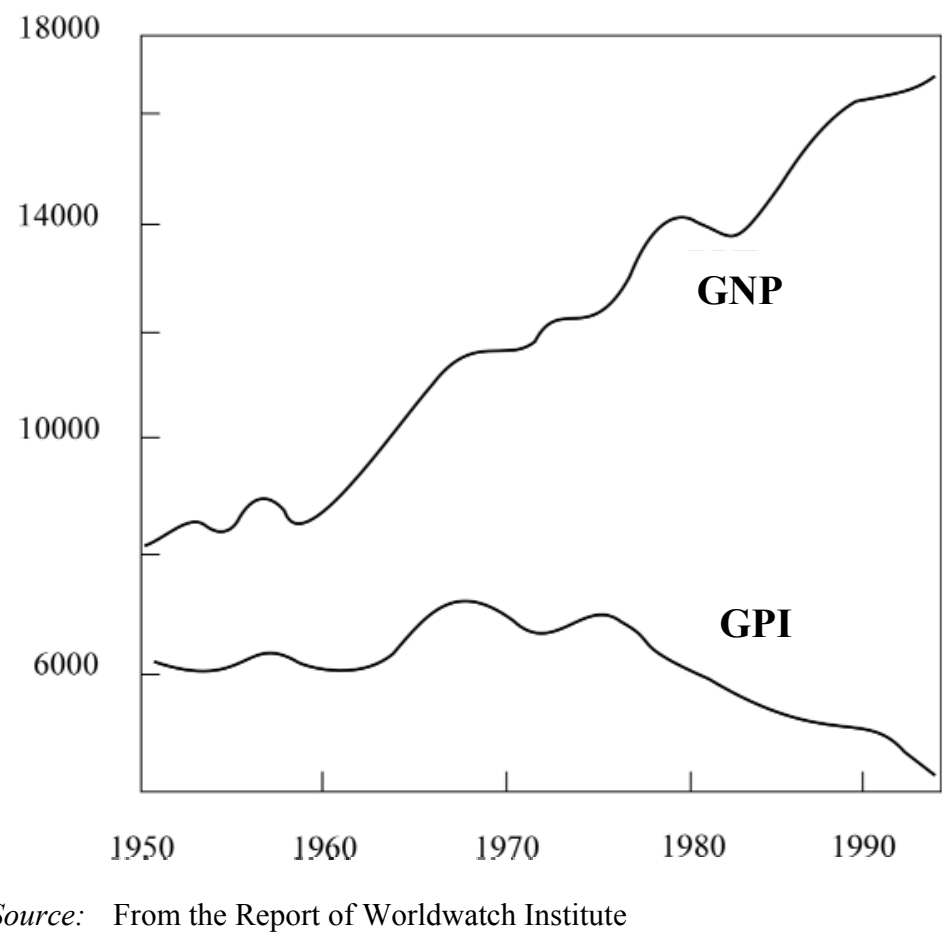

The situation will undoubtedly deteriorate (see Appendixes 1 and 3), which means that in the 21 st century the working paradigm of the quality of life must be replaced by a new one.

According to the HyCi concept, in the 21st century mankind will adopt a new humanitarian-cultural paradigm: a high quality of life will be associated (and accepted) as an optimum combination of good, ecologically clean environments, habitat (first of all) with a reasonable satisfaction of necessary spiritual and material demands. Based on 
this paradigm, a new mass comprehension will serve as humanitarian-cultural basis for a legislative-economic mechanism of transition to $\mathrm{HyCi}$.

The above is a decisive humanitarian and cultural condition facilitating a real motion of mankind to the era of $\mathrm{HyCi}$. So, let us formulate and discuss the main regulations of the legislative-economic mechanism of the transition to the first stage of $\mathrm{HyCi}$, paying attention to the humanitarian-cultural basis of functioning of this mechanism.

To put a question in the way, what in future will define the attainment of an economic benefit of producing and using hydrogen power? In other words, will or won't hydrogen power be acceptable in the future, and will or won't it be in wide demand later as a good of the world market economy?

The answer to this fundamental question is given in the $\mathrm{HyCi}$ concept, which formulates three base regulations of the legislative-economic mechanism of the formation of the hydrogen power market.

\subsection{The first base regulation}

Technical improvement of hydrogen equipment and hydrogen power technologies (that have been successfully proceeding for more than 30 years) will permanently decrease the cost gap between a hydrogen economy that is relatively expensive for the time being and the economy of oil and gas. This tendency is now well observed when analysing the evolution of hydrogen energy and hydrogen economy at the end of the 20th century and the beginning of the 21 st century.

\subsection{The second base regulation}

It is based on the exhaustibility of the world resources of oil and gas: as early as the 1970s this factor was considered as one of the main reasons for a transition to hydrogen energy (to atomic-hydrogen energy in the USSR). At the beginning of the 21 st century this problem arose in a rather critical form and it already dictates negative geopolitical tendencies and decisions. In a foreseeable future ( 2030s) the world economy will begin to experience a real and always increasing deficit of the natural energy resources, first of all oil and gas. In this connection, a modern tendency of instability and increase of prices on oil and gas taking place in the world economy in the near future will take a stable uniform character of only a permanent growth of prices.

It's quite clear that such a line of development of the world market of energy carriers will facilitate the cutting down of a cost gap between hydrogen economy and oil and gas economy.

These two base regulations themselves will stably guarantee the motion to attain an economic benefit of hydrogen power and in a historically foreseeable future will guarantee a stable self-development of the hydrogen market economy. But an important condition of this historical process being stable is a necessity to overcome the 'Hindenburg's syndrome' in mass comprehension and to accept by mass awareness new market products: hydrogen automobiles, hydrogen filling stations and other products of hydrogen engineering and hydrogen power technologies. In essence, the motion in this direction has already begun: here, one can mention international efforts to organise demonstration hydrogen filling stations, demonstration hydrogen automobiles, etc. Already in 2004, the participants of the 15th World Hydrogen Energy Conference in 
Yokohama could take part in trial runs of hydrogen automobiles and buses. The following international hydrogen conferences and exhibitions fixed this tendency. Detailed information on this question can be now found on the internet and in the public press.

\subsection{The third base regulation}

It is first of all based on the indisputable situation that the modern state of the biosphere causes the most serious apprehensions and there is a question about the system crisis of the current civilisation, about the potential of mankind to self-destruction (see Appendixes 1 and 3).

The results of an examination of the evolution of the biosphere for the last two centuries and a synergetic prognosis of its possible ways of development are summarised in Figure 2 (Goltsov et al., 2006a). The results of the synergetic analysis show that the biosphere has already entered (or will enter soon) into a bifurcational period. Then, two alternative ways of the biosphere evolution will be possible. One of them is the motion to a total biospheric catastrophe (see Appendixes 1 and 3) and to a possible end of the existence of the Homo desipiens faber 'empire'. The other one is the motion by an ecologically clean vector 'hydrogen energy $\rightarrow$ hydrogen economy $\rightarrow \mathrm{HyCi}$ '.

Figure 2 The scheme of the historical, current and possible future evolution of the Earth's biosphere

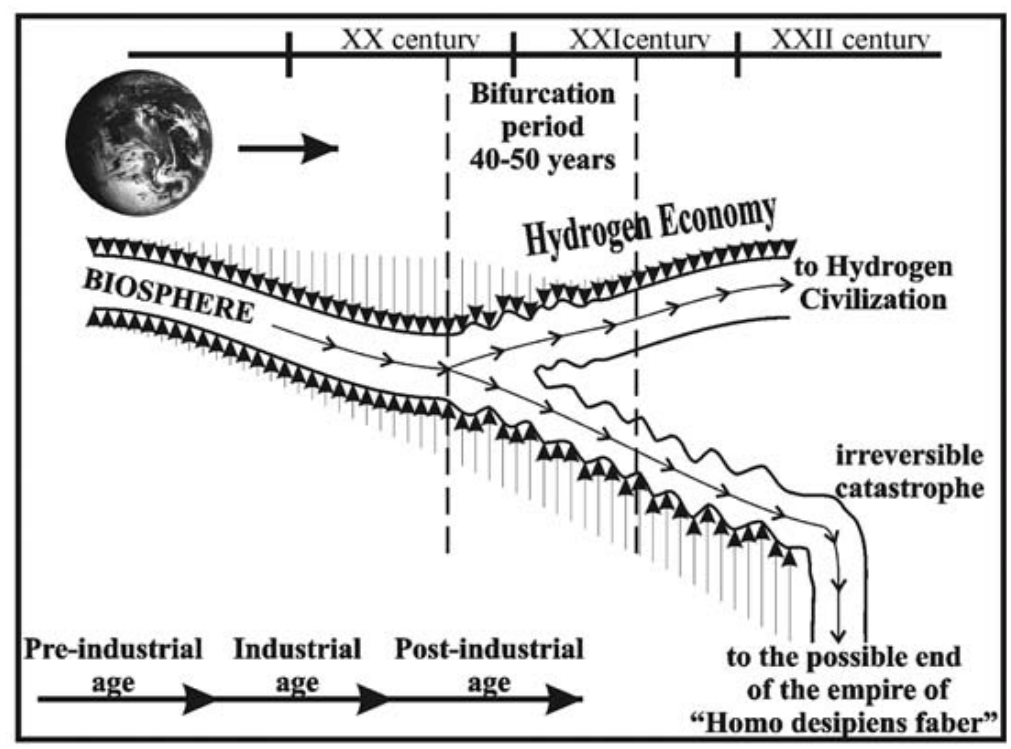

The HyCi concept in its humanitarian and cultural basis reflects a real situation that the mass consciousness of mankind and the elitist comprehension of a significant (even larger) part of the educated society do not perceive, do not comprehend: 
- permanent deterioration of the life quality of the 'golden billion' even (not only the whole of mankind)

- a historically near danger of total biosphere catastrophe (not only the world ecology and climate crisis).

As its basis the HyCi concept takes the slogan of the market economy: "everything must be paid for!" and makes it wider: "everything and the life on the Earth too, must be paid for!"

The HyCi concept asserts that the historical time interval needed to reach the first stage of $\mathrm{HyCi}$ when mankind can already avoid a world-wide ecological catastrophe and save the biosphere acceptable for living can and must be fundamentally shortened. That can and will be attained by changing the paradigm of the quality of life and by introducing a system of ecological taxes.

A possibility of introducing ecological taxes will therewith be fully specified by mass hydrogen-ecological consciousness and, as a whole, by humanitarian-cultural readiness of the population of industrial megalopolises, separate countries, groups of countries, and, at last, by the readiness on a global scale.

So, in addition to the two base regulations given above, just the system use of ecological taxes as the most important constituent of the legislative-economic mechanism of the transition to a $\mathrm{HyCi}$ will be fully based on an obligatory move of the elitist and mass awareness on the hydrogen-ecological path. Moreover, the $\mathrm{HyCi}$ concept asserts that the rate of creating the humanitarian-cultural basis will on the whole specify the rate of movement of mankind along the ecologically clean vector 'hydrogen energy $\rightarrow$ hydrogen economy $\rightarrow$ HyCi'.

The above three base regulations provide the groundwork for the legislative-economic mechanism of HyCi transition that, functioning (by Vernadsky) as a noospheric necessity, will ensure that the world hydrogen economy achieves an economically profitable status and serves as a technical-economic basis of mankind's transition into the era of $\mathrm{HyCi}$.

Now, let's point out the spheres that, according to the $\mathrm{HyCi}$ concept, will be embraced by the future humanitarian-cultural transformation:

- the spheres of human activity forming the mass awareness

a education and upbringing (from the children's preschool till higher and post-university education)

b the mass-media (newspapers, popular editions, radio, television, etc.) and new ones forming informational society (internet and other new electronic mass-media)

c fiction, cinema and other arts

d other ways and means of influencing the mass awareness.

- the spheres of human activity forming the elitist awareness.

a Vernadsky's biosphere and noosphere doctrine in its historical status and nowadays development

b the current geo-ecological studies (including historical geoecology, ecological studies on particular problems, etc. 
c philosophy (including a synergetic concept of the universe and synergetic philosophy of history)

d history (including the history of science and engineering, the concept of synergetic historical method etc.), culturology, sociology, political science, etc.

e economic and socio-economical sciences

f natural and engineering sciences.

According to Vernadsky's logic, one should establish that the motion of such a scope must be and will be really noospheric, and the historical process of forming and taking a new hydrogen-ecological comprehension will capture (in one way or another) the larger part of the world elite: scientific, cultural, administrative, financial, legislative, etc.

Let's now consider the question about a leader. The world hydrogen movement that appeared about 30 years ago thanks to the enthusiasm of 'hydrogen romantics' in the West and in the USSR, now has quite a weighty position in the world and in the leading industrially developed countries. According to the $\mathrm{HyCi}$ concept, the world hydrogen movement should play a catalyst role in the theory elaboration and practical realisation of a $\mathrm{HyCi}$. One should pay attention here to the following important circumstance. An overwhelming majority of the world hydrogen movement are hitherto the representatives of the scientific and engineering elite. In the last years it was joined by the most active part of the industrial-corporative and administrative (international and national) elite. An important conclusion follows that at the present historical stage just the scientific and engineering elite should take upon themselves (strange as it may seem) the role of a leader in working out and realising the humanitarian-cultural basis, the theory and practice of the transition into the era of $\mathrm{HyCi}$. Therewith specialists of humanitarian-social sciences, mass-media, education, etc., must be won over for the teamwork of the future.

The further development and realisation of the HyCi concept will undoubtedly get a noospheric character and will want the efforts of the worldwide scientific and cultural community. In this historical process a special role will belong to the formation and permanent deepening of a new hydrogen-ecological elitist and mass comprehension first in industrial Megalo policies and leader-countries, and then on a global scale.

\section{Conclusions}

On the threshold of the 21 st century there arose pertinent historical conditions for conceiving a new mode of thought about the future of human civilisation, HyCi. It was realised in the form of a novel $\mathrm{HyCi}$ concept.

The $\mathrm{HyCi}$ concept has a pronounced program character and includes three interdependent and interrelated basic constituents: industrial-ecological, humanitarian-cultural, and geopolitical international-legislative ones.

In accordance with the philosophical synergetic concept of the universe, the $\mathrm{HyCi}$ idea (concept) by its content, by its historical maturity and by its attractiveness as a public ideal can (and will) perfectly serve as a 'superattractor', the motion to which will fill the forthcoming history of mankind with a new sense. 
For the first time, there are formulated two future historical stages (two phases) in asymptotic motion of mankind to the $\mathrm{HyCi}$ superattractor, and the distinction between them can be analysed.

There is an idea that under the influence of philosophy, the knots of the theoretical basis of the transition to a $\mathrm{HyCi}$ will be further comprehended in the most generalised view.

The HyCi concept in its humanitarian-cultural basis reflects the world situation that the mass comprehension of mankind and the elitist comprehension of a considerable (and even larger) part of the educated society do not realise yet that the real quality of life of the 'golden milliard' even (not only the whole of mankind) is permanently deteriorating, and especially do not perceive a historically near danger of world-wide ecological catastrophe.

The HyCi concept asserts that a historical time interval needed to reach the first stage of $\mathrm{HyCi}$ when mankind can already avoid the world-wide ecological catastrophe and save the biosphere in a suitable condition for living can and must be shortened. This might be attained by adopting a new humanitarian-cultural paradigm on the quality of life and by introducing a system of ecological taxes.

The rate of forming the humanitarian-cultural groundwork of the transition will fully specify the rate of mankind's motion to the ecologically clean era of the HyCi.

\section{Acknowledgements}

It is a nice duty to express a very deep gratitude to Professor T. Nejat Veziroglu, IAHE President, for the three decades of fruitful cooperation and for the joint work to achieve a deep understanding by the hydrogen community of the nature of the future of human civilisation, HyCi.

The author is very grateful to Dr. J. Bolcich, IAHE Board Director, for his initiative and $\mathrm{HyCi}$ concept discussion at the IAHE Board Directors Meeting in Montreal (2002), for his use of some $\mathrm{HyCi}$ ideas in the realisation of the 'wind hydrogen pilot project in Patagonia', Argentina.

The author offers sincere thanks to Dr. Eng. Lyudmila F. Goltsova for her steady support and help, without which this work was impossible.

\section{References}

Alimova, R.F., Begicheva, T.S., Goltsova, L.F. et al. (1983-1994) 'Bibliography on hydrogen energy and technology', (USSr) International Journal of Hydrogen Energy, 1983, Vol. 8, No. 8, pp.645-668; 1984, Vol. 9, No. 10, pp.873-884; 1985, Vol. 10, No. 12, pp.861-874; 1987, Vol. 12, No. 3, pp.187-204; 1988, Vol. 13, No. 2, pp.111-124; 1989, Vol. 14, No. 1, pp.53-64; 1990, Vol. 15, No. 3, pp.219-234; 1991, Vol. 16, No. 2, pp.147-158; 1992, Vol. 17, No. 2, pp.153-170; 1994, Vol. 19, No. 12, pp.969-989.

Bockris, J.O’M. (1971) Environment, Vol. 13, p.51.

Bockris, J.O’M. (1972) Science, Vol. 179, p.1323.

Bockris, J.O'M. (2001) 'Hydrogen treatment of materials', Proceedings, The Third International Conference 'HTM-2001', Donetsk, Ukraine, pp.33-52. 
Goltsov, V.A. (2001a) 'Biosphere and greenhouse effect intensive growth: is the world environmental catastrophe possible?', Proceedings, International Scientific Conference 'Vernadsky's Creative Heritage and the Present', Donetsk, Ukraine, pp.386-392.

Goltsov, V.A. (2001b) 'Planetary aspects of the humankind transition to the future 'hydrogen civilisation' in the light of Vernadsky's doctrine', Proceedings, International Scientific Conference 'Vernadsky's Creative Heritage and the Present', in Russian, Donetsk, Ukraine, pp.433-439.

Goltsov, V.A. (2002) 'Memorandum on the transition from the fossil system to hydrogen economy and then to hydrogen civilization', International Journal of Hydrogen Energy, Vol. 27, Nos. 7/8, pp.725-726.

Goltsov, V.A. (2007a) Proceedings, Fourth International Scientific Conference 'Vernadsky's Creative Heritage and the Present', Donetsk, Ukraine, pp.267-269.

Goltsov, V.A. (2007b) 'Wisdom of the earth-home. about the world outlook of the 21st century', Ecogeosophic Almanac, Nos. 4/5, Saint-Petersburg-Donetsk, pp.93-106.

Goltsov, V.A. (2007c) Proceedings, Fifth International Conference 'Hydrogen Economy and Hydrogen Treatment of Materials, HTM-2007', Donetsk, Ukraine, pp.37-56.

Goltsov, V.A. (2008) 'Memorandum on a novel IAHE conception of hydrogen civilisation of the future: historical aspects and new challenges of the present day', International Journal of Nuclear Hydrogen Production and Applications, Vol. 1, No. 4, pp.272-277.

Goltsov, V.A. and Goltsova, L.F. (2003a) Proceedings, Third International Scientific Conference 'Vernadsky's Creative Heritage and the Present', Donetsk, Ukraine, pp.203-204.

Goltsov, V.A. and Goltsova, L.F. (2003b) Noosphere, Collection of Philosophical Articles, Donetsk, pp.195-198.

Goltsov, V.A. and Veziroglu, T.N. (2001a) Proceedings, Third International Conference 'Hydrogen Treatment of Materials. HTM-2001', Donetsk-Mariupol, pp. 53-64.

Goltsov, V.A. and Veziroglu, T.N. (2001b) International Journal of Hydrogen Energy, Vol. 26, pp.909-915.

Goltsov, V.A., Veziroglu, T.N. and Goltsova, L.F (2006a) International Journal of Nuclear Hydrogen Production and Applications, Vol. 1, No. 2, pp.112-133.

Goltsov, V.A., Veziroglu, T.N. and Goltsova, L.F. (2004c) 'Hydrogen 2004', Proceedings, 15th World Hydrogen Energy Conference, Yokohama, Japan, CD, No. 30Pl-03.

Goltsov, V.A., Veziroglu, T.N. and Goltsova, L.F. (2006b) International Journal of Hydrogen Energy, Vol. 31, No. 2, pp.153-159.

Goltsova, L.F., Alimova, R.F., Garkusheva, V.A. and Goltsov, V.A. (1990) International Journal of Hydrogen Energy, Vol. 15, No. 9, pp.655-661.

Gregory, D.P. (1973) Sci. Amer., Vol. 227, No. 1, pp.13-21.

Haken, G. (1991) Information and Self-Organization, Macroscopic Point of View on Complicated Systems, Mir, Moscow.

Haken, H. (1983a) Synergetics, An Introduction, 3rd ed., Berlin, Heidelberg, Springer, New York.

Haken, H. (1983b) Advanced Synergetics, Instability Hierarchies of Self-Organizing Systems and Devices, Springer-Verlag, Berlin.

Legasov, V.A. (2007) Khimiya. Energetika. Bezopasnost' (Chemistry. Energy. Safety), in Russian, Nauka, Moscow.

Legasov, V.A. (Editor-in-Chief) (1978-1988) Atomno-Vodorodnaya Energetika i Tekhnologiya, in Russian, Atomizdat, Moscow, Nos. 1-8.

Malyshev, Y.M. (2003) 'Wisdom of the earth-home. about the world outlook of the 21st century', Ecogeosophic Almanac, Nos. 4-5, St-Petersburg-Donetsk, pp.90-110.

Marchetti, C. (1974) J. Brit. Nucl. Energy Soc., Vol. 13, No. 4, pp.353-362.

Ohta, T. (1974) Proceedings, Hydrogen Economy Miami Energy (THEME) Conference, Miami Beach, Florida, March, pp.15-19. 
Ohta, T. (2004) Proceedings, Fourth International Conference 'Hydrogen Treatment of Materials.HTM-2004', Donetsk-Svyatogorsk, Ukraine, pp.3-12.

Ohta, T. (2006) International Journal of Hydrogen Energy, Vol. 31, No. 2, pp.161-166.

Vernadsky, V.I. (1929) La Biosphere, Alcan, Paris.

Vernadsky, V.I. (1945) 'Biosphere and noosphere', American Scientist, Vol. 33, No. 1, pp.1-12.

Vernadsky, V.I. (1988) Works on the Worldwide History of Science, in Russian, Nauka, Moscow.

Vernadsky, V.I. (1991) Scientific Thought as a Planetary Phenomenon, in Russian, Nauka, Moscow.

Veziroglu, T.N. (2000) 'Hydrogen energy progress XIII', in Z.Q. Mao and T.N. Veziroglu (Eds.): Vol. 1, p.3, Beijing, China.

Veziroglu, T.N. (Ed.) (1975) 'Hydrogen energy', Proceedings, Hydrogen Economy Miami Energy (THEME) Conference (Parts A and B), Plenum Press, New York.

Veziroglu, T.N. and Basar, O. (1974) Proceedings, Hydrogen Economy Miami Energy (THEME) Conference, Miami Beach, Florida, March.

Zubakov, V.A. (2007) 'My life in science. Wisdom of the earth-home. about the world outlook of the 21 st century', Ecogeosophic Almanac, Russian-Ukrainian Issue, St-Petersburg-Donetsk, pp.12-19.

Zubakov, V.A. (Ed.) (2003) 'Wisdom of the earth-home. About the world outlook of the 21st century', Ecogeosophic Almanac, Nos. 4/5, St-Petersburg-Donetsk.

\section{Notes}

1 Syn-ergia (Greek) - a common coordinated action, cooperation, participation.

2 It should be emphasised that Verne, a famous French fantasy writer, had many scientific forerunners. For example, in 1820 a Scientist and Engineer W. Cecil in his report submitted to the Cambridge philosophical society, suggested to use hydrogen as a fuel, and in 1822 he published a scientific article in the journal of this philosophical society "on use of gaseous hydrogen for creating motive force in machinery". The first patent on an engine working on a hydrogen-oxygen mixture was granted in England in 1841. In Munich, Germany, in 1852 a Court Watchmaker H. Teitmann made an engine working for some years on a hydrogen-air mixture. In 1839 an English Chemist Sir William Robert Grove created 'a galvanic gaseous battery' - a new electrochemical generator (a fuel cell) that made it possible to obtain electric current with the help of electrochemical reaction of hydrogen and oxygen.

In the first half of the 20th century the scientific and engineering bases of using hydrogen as a fuel were intensively developed. Let's mention here only the outstanding works (1920-1930s) of the automobile engineer and scientist Rudolf Erren (Germany) and an engineering and human feat of the technician and Lieutenant B.I. Scelisch, the latter in Leningrad under blockade provided 400 automobile engines working on hydrogen taken from the balloons that had lost their buoyancy.

But that was Verne who is by right considered as a herald of hydrogen energy, as it was he who attracted a general attention of a wide audience of the last quarter of the 19th century and later to a new possibility for mankind to use hydrogen as a fuel; being burnt it gives only water as a by-product. Following Vernadsky's idea, one can't but emphasise that the example given clearly demonstrates the efficiency of a mutual influence of different types of human thinking: in this case these are scientific and artistic thinking.

3 For example, existing during geological period a solar energy stationary distribution (see Goltsov, 2006a, 2006b) directly consumed by the biosphere and 'given back' into outer space will change. As follows from Vernadsky's studies, such power transformation of the biosphere 'will move' a geological existence of the Earth, the biosphere and mankind as the main geological force. All this will undoubtedly attract the attention of geology, historical eco-geology and other sciences on the Earth - the only currently known planet that has a biosphere and life in their current forms. 


\section{Appendix 1}

\section{From the 20th century world ecological crisis to the 21st century total biosphere catastrophe}

The 20th century human activity led to the global ecological crisis in all possible directions. It cannot be too highly stressed that pollution of the environment - air, water, soil all over the world - has reached a global point. Cross-border pollutant transfer plays a great role: pollutants are spreading over thousands of kilometres from their sources. For example, chemical toxins have been found even in ice of the Antarctic. Therefore, human poisoning by heavy metals, radioactive elements and chemical toxins takes place all over the world. I point only two examples. Lead, a car pollutant, leads to degradation of human brain. Dioxin, a chemical production pollutant, is a much stronger poison than potassium cyanide.

Such direction of civilisation development and the potential in the 21 st century for total biosphere catastrophe has been a subject of a great anxiety of the leading representatives of the world scientific and cultural community during recent decades. There have been published a lot of very deep analytical investigations on the above problems. It is demonstrated (predicted) that, in the middle of 21 st century, toxin onset might be very rapid and non-reversible, similar to an avalanche. Total genetic mutation of humanity could take place.

It is impossible to give references and to name the authors even of the main publications. I'll indicate only the most comprehensive investigations of a great scientist, Professor V.A. Zubakov, a founder of a new science 'historical geoecology' (Zubakov, 2003, 2007). Readers of IJNHPA can communicate with Professor Zubakov by e-mail: inenco@mail.neva.ru.

My conviction is the same. Shakespeare's Hamlet question sounds now on a global scale: "to be, or not to be the humankind: that is the question".

\section{Appendix 2}

\section{A glance over the biosphere and noosphere}

The biosphere, in accordance with Vernadsky's doctrine, is an "...organised, specific crust envelope of the Earth associated (mated) with life". So, the biosphere is bounded first and foremost by the region where life exists, and living matter is a driving force of the evolution of the biosphere over the geological timescale. The upper limit of the biosphere space includes all the troposphere on the verge of the ozone layer (i.e., about $23-25 \mathrm{~km}$ altitude). On the Earth's surface the biosphere includes the entire world ocean, the hydrosphere of the land and of course all dry land of the Earth. It extends to about $16 \mathrm{~km}$ below the Earth's surface.

The living matter of the biosphere consists of all types of microbes, plants, animals and human. The main point of the Vernadsky's doctrine is that during the historical timescale humanity became (and is) the leading driving force of the biosphere development.

The biosphere is permanently in a state of energy and matter exchange with outer space, with the rest of the central part of the Planet Earth and with the upper part of the 
atmosphere. So, the biosphere is in the highest degree a non-equilibrium system, it is a self-organising, synergetic system (see Goltsov, 2006a, 2006b).

From viewpoint of this work I would like to stress only one point of prime importance for the understanding by an educated society of the present time: climate, ecology, human environments and all forms of human activity are no more than constituents of the biosphere, no more than its functioning. It means that every above-mentioned modern human problem of crucial importance can't be solved without paying attention to the biosphere as a unit.

The noosphere, according to Vernadsky, is a special stage of the biosphere development when a dominant driving force of its self-development is science, with human intellectual activity as a general planetary phenomenon.

It is obvious that mankind's movement along the vector 'hydrogen energy $\rightarrow$ Hydrogen economy $\rightarrow$ HyCi' truly is of a noospherical scale and must be based on a human intellectual activity as a general planetary phenomenon.

\section{Appendix 3}

\section{Goltsov: mankind is at the crossroads of $\mathrm{H}_{2}$ civilisation and self-destruction (16th WHEC Daily Report, No. 3, Friday, June 16, 2006, Lyon, France)}

Over the last 5,000 years the human population has increased 144 fold and its energy consumption 2,650 times. Clearly, this trend is non-sustainable and will inevitably lead to self-destruction of mankind, just as primitive reducing bacteria have been destroyed by their own production of oxygen, or as seen in the 16th century painting 'parable of the blind' by Peter Brueghel the Elder, where a group of blind people stands on the verge of a great abyss. "Just like the blind, mankind is running toward its destruction if it does not make the right decisions now", explains Professor Victor Goltsov from the Ukrainian Donetsk Technical University. Goltsov was deeply inspired by the work of the prominent Russian scientist V.I. Vernadsky (1863-1945) who analysed the nature, defined the boundaries and explained the open, synergetic and evolutional nature of the biosphere (a term invented in 1875 by the Austrian geologist Edward Suess). Believing in the strength of human reason, Vernadsky supposed that the collective scientific thought will overcome the negative results of the technological development and will secure the rational transformation (and not annihilation) of the biosphere, for a maximum satisfaction of the material and spiritual demands of mankind. This future evolutionary stage of the biosphere of the Earth was designated by Vernadsky the Noosphere, the sphere of reason (a term introduced in 1922 by a French philosopher and mathematician Edouard Le Roy).

According to Professor Goltsov, the hydrogen community must now establish how much time mankind has before the biosphere and ecosystems will enter into an irrevocable catastrophic phase of self-destruction. In any case the transition to a $\mathrm{HyCi}$ will not be serene, and mankind will have to solve and prevent antagonisms and instabilities occurring during this transition by geopolitical, international and worldwide legislative action. 